\title{
An empirical study on absenteeism in Garment industry
}

\author{
T. S. Nanjundeswaraswamy*
}

Associate Professor, Department of Industrial Engineering \& Management, JSS Academy of Technical Education, Bangalore, India

\section{H R O N I C L E}

Article history:

Received October 28, 2015

Received in revised format

November 28, 2015

Accepted January 28, 2016

Available online

February 1,2016

Keywords:

Absenteeism

Garment industries

Rewards

Production

\section{Introduction}

\subsection{Absenteeism}

Absenteeism of employees in the garment industry is one of the major threats to the organization as well as employees. Absenteeism of employees not only influences on poor utilization of resources, it also influences on the gross income of employees, this reduced gross income of employees leads poor purchasing power of employees, poor family harmony, health and more physical and psychological stress. If we reduce the employee absenteeism, it leads to high purchasing power finally nation growth domestic products (GDP) rate increases. The present research is an attempt to find out the factors which influence on employee absenteeism and their relationships with absenteeism.

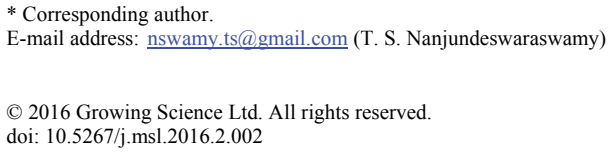

Absenteeism is a major challenge for any organization in the current competitive world. Curbing absenteeism helps organizations achieve their targets and increases productivity. This study highlights the major causes of absenteeism in the production division of a garment industry under various dimensions, which influence on absenteeism like work environment, organizational culture, relation and co-operation, compensation and rewards, facilities, job satisfactory and security, and general factors. The Study helps to identify reasons for employee absenteeism in production division. Sample of 180 employees responses were considered for the study from the universe and the data were analysed, statistically. The study shows that the major factors like wages, other source of income, and bad relationship with supervisors were contributing to the major absence of employees from work. This clearly indicates that work environment, relation and co-operation, facilities provided by the organization and job satisfaction were the main components which are causing the employee absenteeism.

C) 2016 Growing Science Ltd. All rights reserved. 


\subsection{Absenteeism in Indian Garment Industry}

One of the most common problems facing employers in today's workplace is employee absenteeism. Absenteeism, as the term suggests, is simply a matter of employees not showing up for their scheduled work. The effects of absenteeism in the workplace are also directly proportional to decreased productivity and this can also result in the company incurring additional costs to cover for the hiring of temporary staff or paying overtime.

Absenteeism and labour turnover have long been major causes of worry among the garment manufacturers. Every garment organization is trying to put its efforts and polices to curb the absenteeism which is causing a major hurdle to the organization. The first part attempts to highlight issues that can attack on the root cause and reduce the problem and the second part devises a system to minimize its effect on the floor.

Absenteeism is the major implications on the organization with regard to the present developing company like India. We see a number of jobs being outsourced to India and even then the jobs outsourced for the cheap labour are not been utilized by the organizations. The rampant absenteeism in the garment factories in India has been a challenge for the organization, they face productivity loss, recruitment costs and even there is a loss of reputation in the organization. Therefore, the organization should try to understand the major issues and try to implicate those policies, might be the human resource or may be any counselling need to be executed in order to curb the absenteeism in the factories.

\section{Literature Review}

Presently in Indian garment industry, female workforce is more than the male workforce. According to Chandra (2005), most managers and supervisors are male and there is an increasing harassment case towards the female workers. Borda and Norman's (1997) research revealed that the number of children and marital status are variables that represent affinity responsibilities and are considered a major contributor to absence. Cohen and Golan's (2007) research argued that they might lead to higher levels of absenteeism, because of the increased role of demands on employees who are married and have more children. Sinha's (2010) research highlights that there are only 4\% employees remain away from their works for personal reasons. Nisam (2010) stated that stress among employees, health problems, loneliness at workplace, non-cooperation of colleagues causes absenteeism at workplace.

Jacobson (1989) investigated a direct relationship between monetary incentives and work floor attendance. Quddus and Rashid (2000) and Dasgupta (2002) reported that working conditions in the garment industries normally violate international labour standards, and codes of conduct. Bansari (2010) argue that fear of losing jobs and lack of alternative job opportunities force workers to continue in unsatisfactory employment. Paul-Majumder's (1996) research highlights work areas are often overcrowded with limited workspaces, causing occupational hazards such as musculoskeletal disorders and contagious diseases. Injuries, fatalities, disablement and death from fire and building collapses are frequent in the RMG sector. Khan (2011) argued for strengthening social compliance issues and labor standards to improve wages, working hours, overtime, job security, the right to form trade unions, social security and also occupational health and safety to reduce the employee absenteeism. Kearney and Silverman (1993) argue that the causes of absenteeism happen because of family problem. The research on causes of non-attendance has generally focused on family, personal, and school causes.

From the literature the following seven important variables that may influence on absenteeism were found to be very relevant and considered for the present research. They are Work Environment, Organizational Culture, Relation and Co-operation, Compensation \& Rewards, Facilities, Job satisfaction \& Security and General Factors. 


\section{Problem Definition}

There is a high rate of absenteeism in the production division at garment factory. The study mainly focuses on the major reason for the high rate of absenteeism in the production division and what are its implication on the organization and its consequences.

\section{Objectives of the Project}

- To determine the factors which are affecting the absenteeism,

- To study the relationship between various factors and the absenteeism.

\section{Questionnaire development}

From the literature review, it is identified that many components influence on employee absenteeism. Absenteeism is a multidimensional construct and many researchers have used different components to determine the facts for the absenteeism of employees. The questionnaire was designed for research by considering 7 components, which were frequently considered by various researchers, followed by discussion with academicians and HR executives of various firms. The questionnaire was designed both in Kannada and English language. Each section has multiple questions to cover different parameters with a Five-point Likert scale with " 1 " being "strongly disagree" and " 5 " being "strongly agree". The questionnaire consists of 30 close-ended questions.

The reliability coefficient is obtained as 0.88 and hence the questionnaire designed is adequate for exploring research. Since the reliability coefficient was 0.88 Cronbach's alpha value, it was concluded that questionnaire has good reliability.

\section{Sample size}

To represent population reasonably, a sample of size " $n$ " is selected using the following formula found in Hogg and Tannis (1997)

$$
n=\frac{m}{\left[1+\frac{m-1}{N}\right]}
$$

where $\mathrm{n}=$ Sample size, $\mathrm{N}=$ Population size and $m=\frac{\left[\mathrm{Z}^{2} * P *(1-P)\right]}{\varepsilon^{2}}$ with $\mathrm{Z}=1.96$ for $95 \%$ confidence level, $\mathrm{P}=$ Preliminary estimate of percentage ( $85 \%$ I e 0.85$), \varepsilon=$ Accuracy desired ( $5 \%$ i.e. 0.05$)$, which yields sample size $=\frac{\left[1.96^{2} * 0.85 *(1-0.85)\right]}{0.05^{2}}=195.9 \approx 196$. For this $m$ value and the population size $=1464$, the sample size " $n$ " is determined as $n=\frac{196}{\left[1+\frac{196-1}{1464}\right]}=172.72 \approx 173$. Thus, sample size for the study is 180 .

\section{Data Collection and Analysis}

The data was collected through a specially designed questionnaire administered to the 250,198 employees gave filled questionnaires out of that 18 questionnaires were rejected because of invalid and incorrected feedbacks. Finally 180 questionnaires were considered for the analysis. A database was developed to incorporate and process the surveyed data. This database was designed using Microsoft Excel and Minitab 14 software. The responses of the final questionnaire are fed into the designed database for the purpose of analysis and report generation. 


\subsection{Demographic Profile of Respondents}

The demographics profile of the respondents are categorised into four types, like gender, age, experience and marital status etc. and are presented in the Table 1.

Table 1

Respondent characteristics

\begin{tabular}{|c|c|c|c|c|}
\hline Sl no & Characteristics & & No of Respondents & $\begin{array}{l}\text { Percentage of } \\
\text { Respondents }\end{array}$ \\
\hline \multirow{2}{*}{1} & \multirow{2}{*}{ Gender } & Male & 66 & 36.6 \\
\hline & & Female & 114 & 63.3 \\
\hline \multirow{4}{*}{2} & \multirow{4}{*}{ Age } & $<25$ & 71 & 39.01 \\
\hline & & $25-35$ & 72 & 39.50 \\
\hline & & $35-45$ & 26 & 22.52 \\
\hline & & $45>$ & 11 & 6.04 \\
\hline \multirow{4}{*}{3} & \multirow{4}{*}{ Experience } & 3 years & 137 & 76.11 \\
\hline & & $4-10$ years & 35 & 19.44 \\
\hline & & $10-15$ years & 5 & 2.77 \\
\hline & & $15-20$ years & 3 & 1.66 \\
\hline \multirow{3}{*}{4} & \multirow{3}{*}{ Marital status } & Single & 106 & 58.89 \\
\hline & & Married & 73 & 40.56 \\
\hline & & Divorced & 1 & 0.56 \\
\hline
\end{tabular}

Table 1 indicates that $36.66 \%$ of respondents are male and the remaining $63.33 \%$ of female are employees. $39 \%$ of employees are below 25 years of age, $39.50 \%$ of employees are between 25 and 35 years of age, $22.52 \%$ of employees are between 35 and 45 years of age and finally $6.04 \%$ of employees are above 45 years. Table 1 also depicts $76.11 \%$ of employees have less than 3 years of experience, $19.44 \%$ of employees have between 4 to 10 years of job experiences, $2.77 \%$ of employees are between 10 to 15 years of job experiences, and $1.67 \%$ of employees have between 15 to 20 years of job experiences. Table 1 shows $58.89 \%$ of employees are not married, $40.56 \%$ of employees are married, and $0.56 \%$ of employees are divorced.

\subsection{Status of work environment}

To explore the status of work environment in organization, employees were divided into two groups namely, satisfied and unsatisfied, based on their average score. The individual response choices, ranged between 1 to 5 . The maximum average score for an individual is 5, while minimum score is 1 . The two categories of work environment were determined by dividing the range of possible scores (1-5) into two intervals. Those scoring more than the overall mean were assigned as satisfied and those scoring less than overall mean were assigned as unsatisfied. For the present study overall mean is 2.82 .

According to Likert (1932), resulting total score may be interpreted normatively, with reference to some comparison group or absolutely, with reference to theoretically or empirically chosen cut-off scores. In this research overall mean (2.82) is considered as a cut off score. According to Jerome (2013), Vijay Anand (2013), Srinivas and Swamy (2013), Nanjundeswaraswamy and Swamy (2013), Nanjundeswaraswamy, and Swamy (2015) the overall mean is considered as cut off score, above that is satisfied and below the overall mean is considered as unsatisfied with present status of work environment. Table 2 presents the status of work environment. 
Table 2

Status of Work Environment

\begin{tabular}{lcc}
\hline Status of work environment & No of Employees & Percentage \\
\hline Satisfied & 69 & 38 \\
Unsatisfied & 111 & 62 \\
Total & 180 & 100.00 \\
\hline
\end{tabular}

Among 180 respondents, 69 (38 Percent) employees were satisfied with the present status of work environment and 111 (62 percent) were unsatisfied in the organization.

\subsection{Perception of Employees towards organizational Culture and climate}

The perception of employees towards organization culture and climate are categorised into satisfied and unsatisfied on the basis of overall mean. Table 3 presents the perception of employees towards organization culture and climate.

Table 3

Organization Culture and Climate

\begin{tabular}{lcc}
\hline Perception of Organization Culture and Climate & No of Employees & Percentage \\
\hline Satisfied & 99 & 55 \\
Unsatisfied & 81 & 45 \\
Total & 180 & 100.00 \\
\hline
\end{tabular}

Among 180 respondents, 99 (55 Percent) employees were satisfied and 81 (45 percent) were unsatisfied with the present organization culture and climate

\subsection{Status of Relation and Co-operation among employees}

The status of employee relation and cooperation among employees are grouped into satisfied and unsatisfied on the basis of overall mean. Table 4 presents the status of employee relation and cooperation among them.

\section{Table 4}

Relation and cooperation among employees

\begin{tabular}{lcc}
\hline Status of Relation and cooperation & No of Employees & Percentage \\
\hline Satisfied & 71 & 39 \\
Unsatisfied & 109 & 61 \\
\hline Total & 180 & 100.00 \\
\hline
\end{tabular}

Among 180 respondents, 71 (39 Percent) employees were satisfied and 109 (61 percent) were unsatisfied with the present organization culture and climate.

\subsection{Status of Facilities provided by the organization}

The perception of employee towards facilities provided by the organization is grouped into satisfied and unsatisfied on the basis of overall mean. Table 5 presents the perception of employees towards facilities provided by the organization.

\section{Table 5}

Perception of employee towards facilities

\begin{tabular}{lcc}
\hline Status of Facilities provided by the organization & No of Employees & Percentage \\
\hline Satisfied & 84 & 47 \\
Unsatisfied & 96 & 53 \\
\hline Total & 180 & 100.00 \\
\hline
\end{tabular}


Among 180 respondents, 84 (47 Percent) employees were satisfied and 96 (53 percent) were unsatisfied with the present facilities in the organization.

\subsection{Perception Level of Employees towards job satisfaction and security}

The perception of employee towards job satisfaction and security is grouped into satisfied and unsatisfied on the basis of overall mean. Table 6 presents the perception of employees towards job satisfaction and security.

\section{Table 6}

Perception of employee towards Job Satisfaction and Security

\begin{tabular}{lcc}
\hline Status Job Satisfaction and Security & No of Employees & Percentage \\
\hline Satisfied & 71 & 39 \\
Unsatisfied & 109 & 61 \\
Total & 180 & 100.00 \\
\hline
\end{tabular}

Among 180 respondents, 71 (39 Percent) employees were satisfied and 109 (61 percent) were unsatisfied with the job satisfaction and security.

\subsection{Employee family condition and family atmosphere}

The perception of employees towards family condition and family atmosphere is grouped into satisfied and unsatisfied on the basis of overall mean. Table 7 presents the perception of employees towards family condition and family atmosphere.

\section{Table 7}

Employee family Condition and family atmosphere

\begin{tabular}{lcc}
\hline Status of family condition and family atmosphere & No of Employees & Percentage \\
\hline Satisfied & 88 & 48 \\
Unsatisfied & 92 & 52 \\
Total & 180 & 100.00 \\
\hline
\end{tabular}

Among 180 respondents, 88 (48 Percent) employees were satisfied and 92 (52 percent) were unsatisfied with the family condition and family atmosphere.

\subsection{Impact of other source of income to employee absenteeism}

The perception of employees towards other source of income is grouped into satisfied and unsatisfied on the basis of overall mean. Table 8 presents the perception of employees towards absenteeism because of other source of income.

\section{Table 8}

Employee family condition and family atmosphere

\begin{tabular}{lcc}
\hline \multicolumn{1}{c}{ Status of work environment } & No of Employees & Percentage \\
\hline Strongly agree & 114 & 64 \\
Strongly disagree & 66 & 36 \\
Total & 180 & 100.00 \\
\hline
\end{tabular}

Among 180 respondents, 114 (64 Percent) employees were strongly agree other source of income will affect the absenteeism and 66 (36 percent) were strongly disagree. 
7.9 Effect Work environment on absenteeism of employees

Null hypothesis $\left(\mathbf{H}_{\mathbf{0}}\right)$ : Work Environment does not effect on Employee Absenteeism Alternative hypothesis $\left(\mathbf{H}_{\mathbf{1}}\right)$ : Work Environment has an effect on Employee absenteeism.

Table 9

Effect Work environment on absenteeism of employees

\begin{tabular}{|c|c|c|c|c|c|}
\hline Opinions & Respondents & \% Respondents & $\chi^{2}$ Calculated & $\chi^{2}$ Table & Significance level \\
\hline Strongly agree & 14 & 7.8 & \multirow{5}{*}{135.9} & & \multirow{5}{*}{$5 \%$} \\
\hline Agree & 12 & 6.7 & & & \\
\hline Neither agree nor disagree & 13 & 7.2 & & & \\
\hline Disagree & 49 & 27.2 & & 9.488 & \\
\hline Strongly disagree & 92 & 51.1 & & & \\
\hline
\end{tabular}

Inference: In the above Table 9, 7.8\% of respondents strongly agree saying that employee absenteeism causes due to work environment, $6.7 \%$ completely, $7.2 \%$ of respondents are very uncertain. $27.2 \%$ of respondents completely disagree, and $51.1 \%$ strongly disagree. At 4 degrees of freedom at $5 \%$ level of significance calculated $\chi^{2}$ value is more than the $\chi^{2}$ table value i.e. 135.9>9.488. So, $\mathrm{H}_{0}$ is rejected and $\mathrm{H}_{1}$ should be accepted. From chi-square test it can be conclude that the work environment has an impact on employee absenteeism.

\subsection{Effect of the wage policies on absenteeism of employees}

Null hypothesis $\left(\mathbf{H}_{\mathbf{0}}\right)$ : The Wage Policy of the organization has no effect on Absenteeism. Alternative hypothesis $\left(\mathbf{H}_{1}\right)$ : The Wage Policies of the organization has an effect on absenteeism

\section{Table 10}

Effect of the wage policies on absenteeism of employees

\begin{tabular}{|c|c|c|c|c|c|}
\hline Opinions & Respondents & \% Respondents & $\chi^{2}$ Calculated & $\chi^{2}$ Table & Significance level \\
\hline Strongly agree & 24 & 13.4 & \multirow{5}{*}{146.8} & & \multirow{5}{*}{$5 \%$} \\
\hline Agree & 9 & 5.0 & & & \\
\hline Neither agree nor disagree & 10 & 5.6 & & & \\
\hline Disagree & 40 & 22.2 & & 9.488 & \\
\hline Strongly disagree & 97 & 53.8 & & & \\
\hline
\end{tabular}

Inference: According to the results of Table 10, 13.4\% of respondents strongly agree saying that absenteeism is caused by the wages, and 5\% agree with the same, 5.6\% say it's very uncertain, $22.2 \%$ disagree with it, and $53.8 \%$ strongly disagree. At 4 degrees of freedom at $5 \%$ level of significance calculated $\chi^{2}$ value is more than the $\chi^{2}$ table value i.e. 146.89>9.488. So, $\mathrm{H}_{0}$ is rejected and $\mathrm{H}_{1}$ should be accepted. From chi-square test it can be conclude that the wage policies of the organization has an impact on employee absenteeism.

\subsection{Effect of other source of income of employees on absenteeism in the organization}

Null hypothesis $\left(\mathbf{H}_{\mathbf{0}}\right)$ : The other source of income has no effect on employee absenteeism.

Alternative hypothesis $\left(\mathbf{H}_{\mathbf{1}}\right)$ : The other source of income has effect on employee absenteeism

Table 11

Effect of other source of income of employees on absenteeism in the organization

\begin{tabular}{|c|c|c|c|c|c|}
\hline Opinions & Respondents & \% Respondents & $\chi^{2}$ Calculated & $\chi^{2}$ Table & Significance level \\
\hline Strongly agree & 38 & 21.1 & \multirow{5}{*}{82.7} & \multirow{5}{*}{9.488} & \multirow{5}{*}{$5 \%$} \\
\hline Agree & 36 & 20.0 & & & \\
\hline Neither agree nor disagree & 6 & 3.3 & & & \\
\hline Disagree & 21 & 11.7 & & & \\
\hline Strongly disagree & 79 & 43.9 & & & \\
\hline
\end{tabular}


Inference: In the above Table $11,21.1 \%$ say that they strongly agree with other source of income causing absenteeism and $20.00 \%$ of employees agree with it, $3.3 \%$ of employees are very uncertain, $11.7 \%$ of employees completely disagree, and $43.9 \%$ of employees strongly disagree.

At 4 degrees of freedom at $5 \%$ level of significance calculated $\chi^{2}$ value is more than the $\chi^{2}$ table value i.e. $82.7>9.488$. So, Ho is rejected and $\mathrm{H}_{1}$ should be accepted. From chi-square test it can be conclude that the other source of income has an impact on employee absenteeism.

\subsection{Relationship between leadership styles of immediate superiors and employee absenteeism}

Null hypothesis $\left(\mathbf{H}_{\mathbf{0}}\right)$ : Leadership Style of superior has no effect on employee absenteeism. Alternative hypothesis $\left(\mathbf{H}_{\mathbf{1}}\right)$ : Leadership Style of superior has an effect on employee absenteeism.

Table 12

Relationship between leadership styles of immediate superiors and employee absenteeism

\begin{tabular}{|c|c|c|c|c|c|}
\hline Opinions & Respondents & $\%$ Respondents & $\chi^{2}$ Calculated & $\chi^{2}$ Table & Significance level \\
\hline Strongly agree & 92 & 51.1 & \multirow{5}{*}{133.6} & & \multirow[t]{5}{*}{ 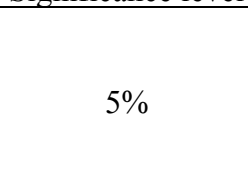 } \\
\hline Agree & 45 & 25.0 & & & \\
\hline Neither agree nor disagree & 4 & 2.2 & & & \\
\hline Disagree & 23 & 12.8 & & 9.488 & \\
\hline Strongly disagree & 16 & 8.9 & & & \\
\hline
\end{tabular}

Inference: From the above Table 12, 51.1\% of respondents say that leadership styles of the superior also causes absenteeism and $25.0 \%$ agree with it and 2.2\% completely say it's uncertain. $12.8 \%$ of respondents disagree, $8.9 \%$ strongly agree. At 4 degrees of freedom at $5 \%$ level of significance calculated $\chi^{2}$ value is more than the $\chi^{2}$ table value i.e. 133.6>9.488. So, Ho is rejected and $\mathrm{H}_{1}$ should be accepted. From chi-square test it can be conclude that the leadership styles of superior has an impact on employee absenteeism.

\subsection{Effect of sickness on absenteeism in the organization}

Null hypothesis $\left(\mathbf{H}_{\mathbf{0}}\right)$ : The Sickness of an employee's has no effect on employee absenteeism. Alternative hypothesis $\left(\mathbf{H}_{\mathbf{1}}\right)$ : The Sickness of an employee's has an effect on employee absenteeism.

Table 7.13

Effect of sickness on absenteeism in the organization

\begin{tabular}{|c|c|c|c|c|c|}
\hline Opinions & Respondents & \% Respondents & $\chi^{2}$ Calculated & $\chi^{2}$ Table & Significance level \\
\hline Strongly agree & 81 & 45.0 & \multirow{5}{*}{100.7} & & \multirow{5}{*}{ (2) } \\
\hline Agree & 53 & 29.4 & & & \\
\hline Neither agree nor disagree & 11 & 6.1 & & & \\
\hline Disagree & 18 & 10.0 & & 9.488 & \\
\hline Strongly disagree & 17 & 9.4 & & & \\
\hline
\end{tabular}

Inference: In the above Table $45.00 \%$ of employees strongly agree saying that sickness has caused them to be absent from work and $29.4 \%$ of employees agree with it, $6.1 \%$ of employees neither agree nor disagree, $10 . \%$ of employees completely disagree, $9.4 \%$ strongly disagree.

At 4 degrees of freedom at $5 \%$ level of significance calculated $\chi^{2}$ value is more than the $\chi^{2}$ table value i.e. 100.7>9.488. So, Ho is rejected and $\mathrm{H}_{1}$ should be accepted. From chi-square test it can be conclude that the Sickness of an employee's has an impact on absenteeism.

\subsection{Effect of Job Security on absenteeism in the organization}

Null hypothesis $\left(\mathbf{H}_{\mathbf{0}}\right)$ : The Job Security has no effect on employee absenteeism. Alternative hypothesis $\left(\mathbf{H}_{\mathbf{1}}\right)$ : The Job Security has an effect on employee absenteeism. 
Table 14

Effect of Job Security on absenteeism in the organization

\begin{tabular}{|c|c|c|c|c|c|}
\hline Opinions & Respondents & \% Respondents & $\chi^{2}$ Calculated & $\chi^{2}$ Table & Significance level \\
\hline Strongly agree & 11 & 6.1 & \multirow{5}{*}{104.9} & & \multirow{5}{*}{ 的 } \\
\hline Agree & 7 & 3.9 & & & \\
\hline Neither agree nor disagree & 26 & 14.4 & & & \\
\hline Disagree & 59 & 32.8 & & 9.488 & \\
\hline Strongly disagree & 77 & 42.8 & & & \\
\hline
\end{tabular}

Inference: Here $6.1 \%$ of respondents strongly agree saying that job security causes absence from work and $3.9 \%$ agree with it, where as $14.4 \%$ of respondents are very uncertain with the same, and $32.8 \%$ of respondents completely disagree saying that it and $42.8 \%$ of respondents strongly disagree with the same. At 4 degrees of freedom at $5 \%$ level of significance calculated $\chi^{2}$ value is more than the $\chi^{2}$ table value i.e. 104.9>9.488. So, $\mathrm{H}_{0}$ is rejected and $\mathrm{H}_{1}$ should be accepted. From chi-square test it can be conclude that the job security has an impact on absenteeism.

\subsection{Mean and the Standard Deviation of the Components}

\section{Table 15}

Mean and the Standard Deviation of the Components

\begin{tabular}{llcc}
\hline & Components & Mean & SD \\
\hline 1 & Work environment & 2.7 & 0.83 \\
2 & Organization culture and climate & 3.2 & 0.73 \\
3 & Relation And co-operation & 2.66 & 0.54 \\
4 & Facilities & 2.61 & 0.68 \\
5 & JOB Satisfaction and Security & 2.71 & 0.61 \\
6 & Family and other Problems & 3 & 1.14 \\
7 & General Factors & 3.3 & 0.93 \\
\hline
\end{tabular}

Inference: In the above table for all the components except organization culture and climate, general factors mean is less than median. This indicates that work environment, relation and cooperation, facilities provided by the company and job satisfaction are the main factors which are promoting for employees absenteeism.

\section{Result and Conclusion}

From Chi Square Test it is found that

The relationship between employees and superior had an effect on employee absenteeism. The grand average for relationship with supervisor is 2.3 , which indicates there is no good and motivating relationship between employees and immediate supervisor in the organization.

$>$ From the chi-square analysis it can be concluded that the other sources of income had high effects on employee absenteeism.

$>$ From the chi-square analysis it can be concluded that the work environment had an impact on employee absenteeism. The grand average for work environment is 2.7 , which indicates work environment is not motivating employees to work in the organization.

$>$ From the chi-square analysis it can be concluded that the job security had an effect on employee absenteeism. The grand average for job security is 2 , which indicates that there was no job security in the in the organization.

$>$ From the chi-square analysis it can be concluded that the relationship between employees and superior had an effect on employee absenteeism. The grand average for relationship with supervisor is 2.3; which indicates there is no good and motivating relationship between employees and immediate supervisor in the organization. 
From the above analysis it can be concluded that the wage policies had an impact on employee absenteeism. The grand average for wage and incentives is 2 , which indicates very poor wage scheme in the organization.

$>$ The Mean of work environment is 2.7, Relation and co-operation is 2.6, Facilities is 2.6, Job satisfaction is 2.7.These numbers clearly indicate that work environment, relation and cooperation, facilities provided and job satisfaction were the main factors which are causing the employee absenteeism.

\section{References}

Anand, V. (2013). Quality of work life among employees in Indian textile industry-A pragmatic approach. Global research analysis, 2(5), 153-154.

Bansari, N. (2010). Textile and clothing sector in post MFA regime: A case from Bangladesh, gender and trade, commonwealth secretariat.

Borda, R. G., \& Norman, I. J. (1997). Factors influencing turnover and absence of nurses: a research review. International Journal of Nursing Studies, 34(6), 385-394.

Chandra, P. (2005). The textile and apparel industry in India. Indian Institute of Management, Ahmedabad.

Cohen, A., \& Golan, R. (2007). Predicting absenteeism and turnover intentions by past absenteeism and work attitudes: An empirical examination of female employees in long term nursing care facilities. Career Development International, 12(5), 416-432.

Dasgupta, S. (2002). Attitudes towards trade unions in Bangladesh, Brazil, Hungary and Tanzania. International Labour Review, 141(4), 413-440.

Hogg, R. V., \& Tannis, E. A. (1997). Statistical Analysis and Inference.PRANTICE HALL.

Jacobson, S. L. (1989). The effects of pay incentives on teacher absenteeism. Journal of Human Resources, 24(2), 280-286.

Jerome, S. (2013). A study on quality of work life of employees at Jeppiaar Cement Private Ltd: Perambalur. International Journal of Advance Research in Computer Science and Management Studies, 1(4), 49-57.

Kearney, C. A., \& Silverman, W. K. (1993). Measuring the function of school refusal behavior: The School Refusal Assessment Scale. Journal of Clinical Child Psychology, 22(1), 85-96.

Khan, S. (2011). Labour unrest and compliance issue in garment sector. Financial Express, 18(231).

Likert, R. (1932). A technique for the measurement of attitudes. Archives of psychology.

Nanjundeswaraswamy, T. S., \& Swamy, D. R. (2013). Quality of work life of employees in private technical institutions. International Journal for Quality Research, 7(3), 431-441.

Nanjundeswaraswamy, T. (2015). Leadership styles and quality of work life in SMEs. Management Science Letters, 5(1), 65-78.

Nisam (2010). Ways to reduce employee absenteeism with special reference to united electrical industries Ltd. Kollam, Technical Report, 53-54.

Paul-Majumder, P. (1996). Health Impact of Women's Wage Employment: A Case Study of the Garment Industry of Bangladesh. The Bangladesh Development Studies, 24(1/2), 59-102.

Paul-Majumder, P., \& Begum, S. (2000). The gender impacts of growth of export-oriented manufacturing in Bangladesh: case study: Ready made garment industry Bangladesh. A background paper prepared by the Bangladesh Institute of Development Studies (BIDS) for the World Bank, Dhaka, Bangladesh.

Quddus, M., \& Rashid, S. (2000). Entrepreneurs and Economic Development: the remarkable story of garment exports from Bangladesh. University Press.

Srinivas, R., \& Swamy, D. (2013). Quality Management Practices In Rural And Urban SMEs-A Comparative Study. International Journal for Quality Research, 7(4), 479-492.

Sinha, R. (2010). Absenteeism of employees at Indchemie Health Specialities Pvt. Ltd. Mumbai, Academy of Management Studies, Dehradun.

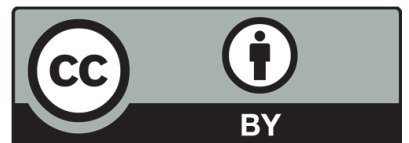

(C) 2016 by the authors; licensee Growing Science, Canada. This article is an open access article distributed under the terms and conditions of the Creative Commons Attribution (CC-BY) license (http://creativecommons.org/licenses/by/4.0/). 